\title{
Radioembolization of Yttrium-90 Microspheres for Clinical Treatment of Hepatic Malignancy
}

\author{
Sahar Alee Koloukani ${ }^{1}$, Ailin $\mathrm{Cao}^{2}$ and Qi Cao ${ }^{{ }^{*}}$ \\ ${ }^{1}$ Department of Diagnostic radiology and Nuclear Medicine, University of Maryland School of Medicine, 22 South Greene Street, Baltimore, Maryland 21201, USA \\ ${ }^{2}$ School of Science and Art, University of Pennsylvania, 120 Claudia Cohen Hall, 249 South 36th Street, Philadelphia, PA 19104,USA
}

*Corresponding author: Qi Cao, Assistant Professor, Department of Diagnostic radiology and Nuclear Medicine, University of Maryland School of Medicine, 22 South Greene Street, Baltimore, Maryland 21201, USA, Tel: 410 -328-9586; Fax: 410-328-1600; E-mail: qcao@umm.edu

Received date: Jun 06, 2014, Accepted date: Jul 29, 2014, Publication date: Jul 31, 2014

Copyright: ( $) 2014$ Koloukani SA, et al. This is an open-access article distributed under the terms of the Creative Commons Attribution License, which permits unrestricted use, distribution, and reproduction in any medium, provided the original author and source are credited.

\begin{abstract}
Trans hepatic arterial radioembolotherapy using yttrium-90 microspheres represents in situ therapy in hepatocellular cancer, which is the third leading cause of cancer-related deaths in the world. This therapy shows interesting results in the treatment of these patients. This review focuses on clinical application, advantages, sideeffects and toxicity, and contradictions of the radioembolization treatment program
\end{abstract}

Keywords: Liver cancer; Yttrium-90; Radioembolization; Technetium- ${ }^{99} \mathrm{M}$; Macroaggregated; Albumin; ${ }^{90} \mathrm{Y}$ PET/CT; ${ }^{99} \mathrm{mTc}-$ MAA SPECT/CT

\section{Introduction}

Hepatocellular cancer (HCC) is the third leading cause of cancerrelated deaths in the world [1-3]. The incidence of HCC is increasing in the United States due to increasing infections with Hepatitis B and C. Although the definite cure includes surgical intervention and liver transplant, yet, in many patients, general medical contraindications, unfavorable tumour characteristics and complications like portal hypertension leave a vast majority of tumours unresectable or even poor candidates for trans-arterial chemoembolization (TACE) [4-8].

Selective internal radiation therapy (SIRT) is a new developing method using yttrium element $[9,10]$. The hypothesis behind this treatment is indebted to the unique hepatic blood circulation and its distinguished characteristics in a cancerous liver. While a healthy normal liver receives around 80 percent of its blood supply from the portal vein, this proportion is reversed in case of hepatic carcinoma and its metastases. The affected liver would be supplied 80 percent by hepatic artery and only 20 percent by portal vein [11-13].

${ }^{90} \mathrm{Y}$ microsphere is an artificial radioactive isotope of the element yttrium, used in selective beam radiotherapy, SIRT, as a part of a multidisciplinary approach mainly for treating the hepatocellular carcinoma and its metastases $[14,15]$. The concept of using SIRT first started to be developed by a Surgeon form New York who was a frontier in applying radioisotopes in clinical diagnosis and therapy [16]. ${ }^{90} \mathrm{Y}$ is produced by bombardment of yttrium 89 with neutrons in a nuclear reactor. It has a physical half-life of 64.2 hours (2.67 days), and it decays to stable zirconium $90 .{ }^{90} \mathrm{Y}$ emits pure high-energy beta rays (energy maximum, $2.27 \mathrm{MeV}$; mean, $0.9367 \mathrm{MeV}$ ) with an average penetration range of $2.5 \mathrm{~mm}$ and a maximum range of $11 \mathrm{~mm}$ in tissue. One gigabecquerel $(27 \mathrm{mCi})$ of ${ }^{90} \mathrm{Y}$ delivers a total absorbed radiation dose of $50 \mathrm{~Gy} / \mathrm{kg}$. In therapeutic use in which the isotope decays to infinity, $94 \%$ of the radiation is delivered in 11 days. There are currently two commercially available microsphere devices in which ${ }^{90} \mathrm{Y}$ is incorporated: one with microspheres made of glass
(Thera-Sphere; MDS Nordion, Ottawa, Ontario, Canada) and the other with microspheres made of resin (Sir-Spheres; Sirtex Medical, Sydney, Australia) [17].

\section{Clinical Application}

${ }^{99} \mathrm{mTc}$-macroaggregated albumin $\left({ }^{99} \mathrm{mTc}-\mathrm{MAA}\right)$ is a necessary step before applying the therapy [18]. To minimize the possible spreading of radioisotope to the intact hepatic tissue as well as the nearby organs, the possible arterial shunts should be embolized prior to applying ${ }^{90} \mathrm{Y}$. No need to say that the bigger tumour is, the more extensive the collateral arterial supplies are. Therefore, mapping the blood supply with ${ }^{99} \mathrm{mTc}-\mathrm{MAA}$ is routinely performed before applying the therapy. Although the embolization of Gastro-duodenal artery (GDA) is greatly performed to reduce the spreading of radioisotope to unnecessary locations, still in some cases, despite coiling of GDA, there would be some spreading into other parts of gastrointestinal organs. However, in some cases as if a retrograde flow exists, keeping the GDA patent during the procedure seems to have a minimum or no role in increasing the related mortality [18-20].

After two injections of ${ }^{99} \mathrm{mTc}-\mathrm{MAA}$ are done via the hepatic catheter, SPECT images of the liver and the whole body scan are acquired to analyze the existence of extra-hepatic shunt via calculation of count ratio of the lungs/(liver+lungs) (Figure 1). The imaging will evaluate abnormal lung uptake when there is an extra-hepatic shunt. ${ }^{99}$ mTc-MAA scintigraphy scan is routinely performed for lung perfusion imaging and for the assessment of in vivo distribution of ${ }^{90} \mathrm{Y}$ - SIRSpheres prior to selective internal radiation treatment for hepatocellular carcinoma. Positron emission tomography (PET) imaging is superior to gamma scintigraphy in terms of sensitivity, spatial resolution and accuracy of quantification. A recent study reported that ${ }^{18} \mathrm{~F}$-labeled macroaggregated albumin $\left({ }^{18} \mathrm{~F}-\mathrm{MAA}\right)$ is an ideal PET imaging surrogate for ${ }^{99} \mathrm{mTc}-\mathrm{MAA}$ in rats [19]. Starting from commercial MAA kit, an efficient preparation of ${ }^{18} \mathrm{~F}-\mathrm{MAA}$ was successfully established. Highly correlated, almost parallel, regional distribution of ${ }^{18} \mathrm{~F}-\mathrm{MAA}$ and ${ }^{99} \mathrm{mTc}-\mathrm{MAA}$ in both normal rats and hepatoma-bearing rats was observed. 


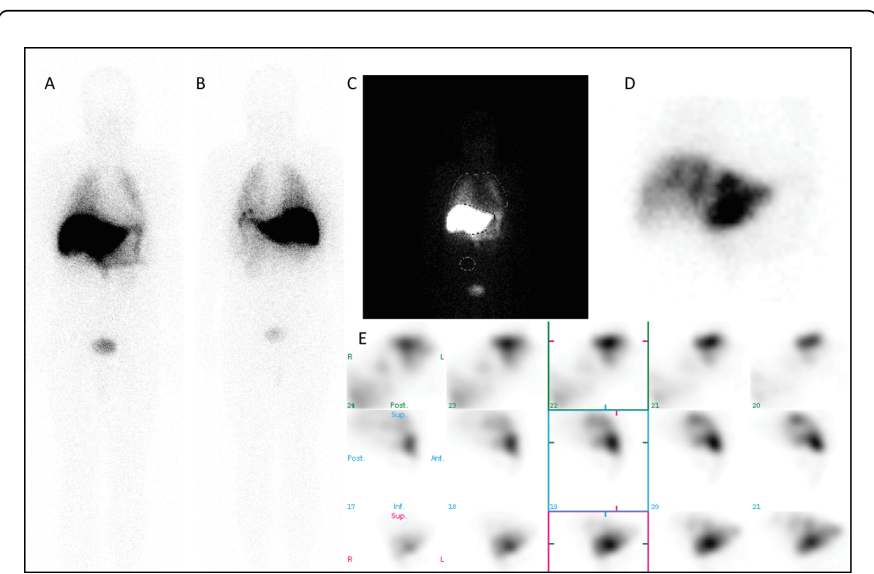

Figure 1: 64 years old female with history of colon cancer with hepatic metastasis presented with Sir-Sphere radio-embolization. 4.29 And $4.25 \mathrm{mCi}$ of ${ }^{99} \mathrm{mTc}-\mathrm{MAA}$ was injected during the hepatic angiography followed by SPECT images of the liver as well as the whole body scan. Whole body planar images and SPECT images of the liver showed intensive uptake in the liver. On the review of the whole body images, there was minimal activity in the lungs. Count ratio of the lungs/ (liver+lungs) was calculated to be $3.25 \%$. There was no abnormal radiotracer accumulation in the stomach or elsewhere in the body. A, ${ }^{99} \mathrm{mTc}$ MAA whole body anterior and B, posterior views, C, ROIs of lungs and liver, D, SPECT view of abdomen, and E, three dimension SPECT of the liver.

After extra-hepatic shunts are ruled out, patients will be then treated with ${ }^{90} \mathrm{Y}$ microspheres. 24-48 hours later after the administration of ${ }^{90} \mathrm{Y}$ microspheres via arterial catheter, anterior and posterior whole body bremsstrahlung scans are acquired, followed by SPECT tomographic imaging of the liver region (Figure 2). These images assist referring physicians to determine whether or not $90 \mathrm{Y}$ microspheres is within the liver lobes of radioactive targeted tumour and to find any evidence for pulmonary or gastric shunts. The modalities of SPECT or SPECT/CT images are currently replaced by ${ }^{90} \mathrm{Y}$ microspheres PET/CT in our hospital (Figure 3). In general, the advantage of PET/CT imaging is high resolution on PET and definite anatomic structure on CT in tumour imaging (Figure 3).

The way to determine the suitable dosage to give the drug is either consistent with body mass index (BMI) or applying partition model dosimetry. In a study done by Kao, et al. [21], partition model dosimetry is more useful in applying ${ }^{90} \mathrm{Y}$ due to limitation of body surface area (BSA) method in over or under treatment in some patients. They put their comparison in two tables to show advantages and disadvantages of both methods [21-23].

Series of clinical trials demonstrate that the utility of ${ }^{90} \mathrm{Y}$ microsphere radioembolization therapy is safe and it exhibits antitumoural response and survival benefit in select patients with primary and secondary liver cancers [24-27]. Results are most pronounced in patients with solitary tumours, for whom conversion to curative resection is possible. The clinical usage of ${ }^{90} \mathrm{Ymicrosphere}$ radioembolization focuses on treating the unresectable hepatic cancer either primary or the metastases like colorectal tumours [28-30], testicular liver metastasis [31], and unresectable intrahepatic cholangiocarcinoma [32-34], metastatic neuroendocrine tumours [35], and breast cancer liver metastasis [36].

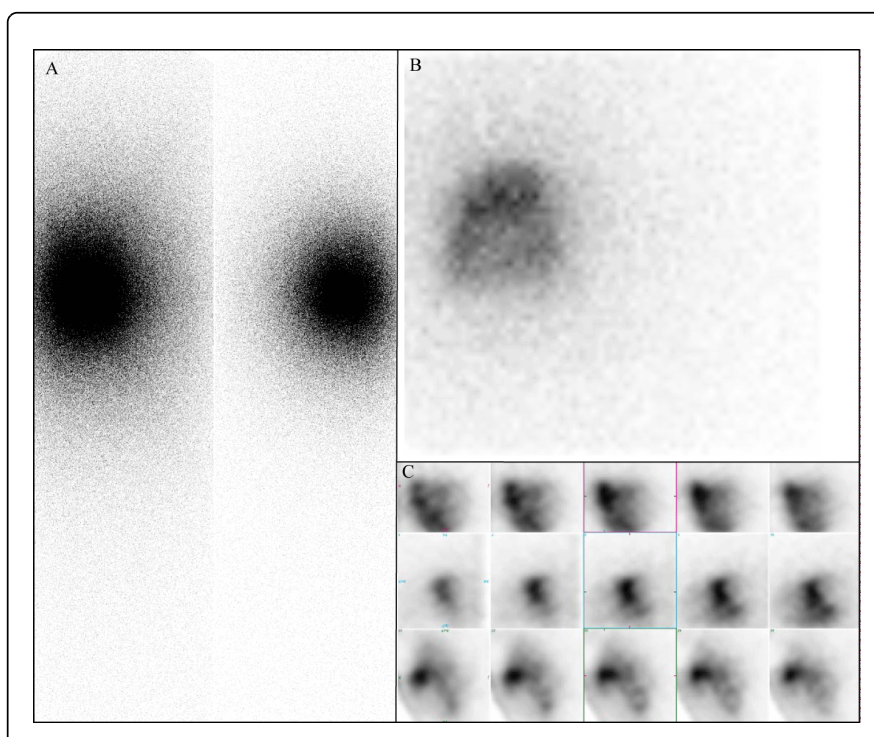

Figure 2: 64 years old female with history of colon cancer with hepatic metastasis presented with Sir-Sphere radio-embolization. $34.7 \mathrm{mCi}$ Sir-Sphere radio-embolization of the right hepatic artery, the whole body anterior and posterior images, SPECT view of abdomen, and SPECT liver images were obtained. A, ${ }^{90} \mathrm{Y}$ Sir-Sphere whole body anterior and posterior views, B, SPECT view of the abdomen, and C. three dimension SPECT of the liver.

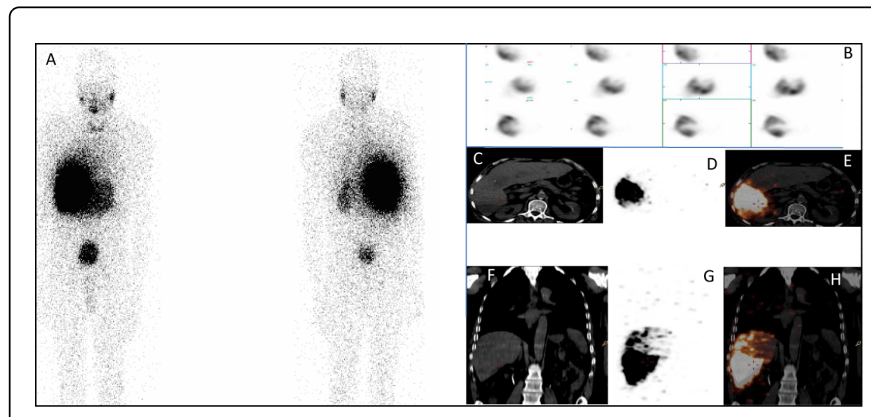

Figure 3: 61 years old male with history of hepatocellular carcinoma presented with Sir-Sphere radio-embolization. After $39.5 \mathrm{mCi}$ SirSphere radio-embolization through the right hepatic artery, the PET images were obtained, reconstructed, and viewed using volume rendering. Localizing CT scan was performed using a standard spiral MDCT protocol imaging the chest, abdomen and pelvis with $5 \mathrm{~mm}$ slices. CT and PET data was fused for image interpretation. PET/CT images showed heterogenous radiotracer distribution in the right hepatic lobes. There is no other radiotracer activity throughout the imaged portion of the body. A, ${ }^{99} \mathrm{mTc}-$ MAA whole body anterior and posterior views, B, SPECT view of the abdomen, $\mathrm{C}-\mathrm{H},{ }^{90} \mathrm{Y}$ Sir-Sphere PET/CT images, C, Axial CT view, D, Axial PET view, E, Fused axial view, F, Coronal CT view, $\mathrm{G}$, Coronal PET view, and $\mathrm{H}$, Fused coronal view. 
Accumulating clinical data would provide fundamental guidance for clinical and therapeutic efforts for disease types for which clinical trials are not feasible due to their low incidence or for the vast majority of those afflicted who do not meet eligibility criteria.

108 consecutive patients with advanced HCC and liver cirrhosis were treated with ${ }^{90} \mathrm{Y}$ microspheres administered over the right or left branch of the hepatic artery. 159 treatment sessions were performed ranging between one to three treatments per patient. The mean radiation dose per treatment was 120 (618) Gy. According to the European Association for the Study of the Liver (EASL) criteria, complete responses were determined in $3 \%$ of patients, partial responses in $37 \%$, stable disease $53 \%$, and primary progression in $6 \%$ of patients. Time to progression (TTP) was 10.0 months, whereas the median overall survival was 16.4 months. No lung or visceral toxicity was observed. This clinical study demonstrated that radioembolization with ${ }^{90} \mathrm{Y}$ glass microspheres for patients with advanced HCC was a safe and effective treatment which could be utilized even in patients with compromised liver function [37]. In comparison to chemoembolization, another clinical study showed that radioembolization had less systemic toxicity and could be performed as an outpatient procedure, which makes it more attractive to both patients and physicians. The radioembolization procedure is considered as a promising first-line treatment in unresectable liver cancer [38]. ${ }^{90} \mathrm{Y}$ radioembolization in patients with HCC who have received sorafenib demonstrate acceptable toxicity and rates of radiographic response. However, the overall survival is lower than that reported in the literature on radioembolization alone or sorafenib alone. This may be due in part to more patients in this study having advanced disease compared to these other study populations. Larger prospective studies are needed to determine whether the combination of radioembolization and sorafenib is superior to either therapy alone [39]. Hypertrophy of the contralateral liver lobe after treatment with ${ }^{90} \mathrm{Y}$ microspheres has recently been reported. This study quantified left liver lobe hypertrophy after right-sided radioembolization for HCC and identified pre-treatment predictive factors of hypertrophy in an Asian population. Administration of unilobar SIRT to the right liver lobe in patients with HCC resulted in a significant degree of contralateral left lobe hypertrophy. Patients with hepatitis B experienced a greater degree of hypertrophy compared to patients with hepatitis $\mathrm{C}$ or alcoholic liver cirrhosis [40].

The majority of patients with advanced colorectal cancer die from hepatic metastases caused by disease progression; radioembolization was a technique for administering radiotherapy internally to unresectable secondary hepatic malignancies in a single procedure. Several reports suggested that radioembolization was associated with significant downsizing of liver metastases to permit subsequent surgical resection. Clinical data from trials of radioembolization with concomitant systemic treatment also emphasized the appropriateness of primary end points in large-scale trials and the practical aspects of surgical resection in patients whose tumours were successfully downsized by this chemo radiation approach [28,29]. 41 patients affected by colorectal cancers from a cohort of selective internal radiation therapy patients with disease progression by an abdominal $\mathrm{CT}$, a body PET, and a hepatic angiography were underwent for treatment of ${ }^{90} \mathrm{Y}$ radio-embolism. Side effects by Common Terminology Criteria on Adverse Events were represented by one grade 4 hepatic failure, two grades 2 gastritis, and one grade 2 cholecystitis. The median survival and the progression-free survival calculated by Kaplan-Meier analysis were 354 and 279 days, respectively. This clinical study demonstrated that ${ }^{90} \mathrm{Y}$ SIR-Spheres radioembolization is a feasible and safe method to treat colorectal cancers liver metastases, with an acceptable level of complications and a good response rate [31].

Recent clinical study showed a total of 214 patients with colorectal cancers liver metastases were treated with ${ }^{90} \mathrm{Y}$ radioembolization. Survival was significantly longer in patients who received $\leq 2$ cytotoxic drugs and who received no biologic agents. Multivariate analyses identified $\leq 2$ cytotoxic agents, no exposure to biologics, ECOG 0, tumour burden $<25 \%$, lack of extrahepatic disease and albumin $>3$ $\mathrm{g} / \mathrm{dL}$ as independent predictors of survival. The data indicated that ${ }^{90} \mathrm{Y}$ radioembolization was found to be safe; survival varied by prior therapy [41].

Another recent clinical report showed asystematic review of clinical studies before November 2012 with twenty studies comprising 979 patients. The average reported value of patients with complete radiological response, partial response and stable disease was $0 \%, 31 \%$ and $40.5 \%$, respectively. The median overall survival was 12 months. The overall acute toxicity rate ranged from 11 to $100 \%$ (median $40.5 \%$ ). Most cases of acute toxicity were mild (Grade I or II) (median $39 \%$; range 7-100\%) which resolved without intervention. The number of previous lines of chemotherapy $(\geq 3)$, poor radiological response to treatment, extra-hepatic disease and extensive liver disease $(\geq 25 \%)$ were the factors most commonly associated with poorer overall survival. ${ }^{90} \mathrm{Y}$ radioembolization overall is a safe and effective treatment of chemorefractory colorectal cancer liver metastases in the salvage setting and should be more widely utilized [25].

24 patients with unresectable standard-chemorefractory intrahepatic colangiocarcinoma (ICC) treated with ${ }^{90} \mathrm{Y}$ were studied for analysis for survival, tumour response and complications. Median survival from the time of diagnosis and first ${ }^{90} \mathrm{Y}$ procedure was $752 \pm$ 193 and $345 \pm 128$ days, respectively. Median survival with Eastern Cooperative Oncology Group (ECOG) performance status and ECOG performance status 2 was $450 \pm 190$ and $345 \pm 227$ days, respectively $(\mathrm{p}=.214)$. Patients with extra hepatic metastasis had a median survival of $404 \pm 309$ days versus $345 \pm 117$ days for patients without metastasis $(\mathrm{p}=.491)$. No mortality was reported within 30 days from first ${ }^{90} \mathrm{Y}$ radioembolization. One patient developed grade 3 thrombocytopenia as assessed by NCI CTCAE. Fatigue and transient abdominal pain were observed in $4(21 \%)$ and $6(32 \%)$ patients, respectively. The study indicated ${ }^{90} \mathrm{Y}$ radioembolization is effective for unresectable standardchemorefractory ICC [33].

The present study expands on the cohort of 24 patients with ICC described in a pilot study, and includes 46 patients treated with (90)Y radioembolization during an 8 -year period. Patients were stratified by performance status, tumour distribution (solitary or multifocal), tumour morphology (infiltrative or peripheral), and presence/absence of portal vein thrombosis. Ninety-two treatments were performed, with a mean of two per patient. Fatigue and transient abdominal pain occurred in 25 patients (54\%) and 13 patients (28\%), respectively. Treatment-related gastroduodenal ulcer developed in one patient (2\%). WHO imaging findings included partial response $(\mathrm{n}=11 ; 25 \%)$, stable disease $(n=33 ; 73 \%)$, and progressive disease $(n=1 ; 2 \%)$. EASL imaging findings included partial/complete response $(n=33 ; 73 \%)$ and stable disease $(n=12 ; 27 \%)$. Survival varied based on presence of multifocal (5.7 mo vs $14.6 \mathrm{mo}$ ), infiltrative ( $6.1 \mathrm{mo}$ vs $15.6 \mathrm{mo}$ ), and bilobar disease (10.9 mo vs $11.7 \mathrm{mo}$ ). Disease was converted to resectable status in five patients, who successfully underwent curative (i.e., R0) resection. Radioembolization with ${ }^{90} \mathrm{Y}$ is safe and demonstrates antitumoural response and survival benefit in select 
Page 4 of 6

patients with ICC. Results are most pronounced in patients with solitary tumours, for whom conversion to curative resection is possible [32]. Another study was performed in patients with recommended for unresectable, chemorefractory liver-dominant disease. Addition of FDG-PET/CT images showed significantly more extrahepatic diseases and led to a considerable change of management [34].

For patients with biopsy-proven, chemotherapy-resistant testicular cancer, liver metastasis was successfully treated with ${ }^{90} \mathrm{Y}$ radioembolism selective internal radiation treatment. The result was marked tumour response by PET/CT as well as significant improvement of the patient's quality of life accompanied by a substantial decrease of his tumour markers [31].

A study was carried out to evaluate the anatomic and physiologic determinants of radiation dose distribution, and the dose response of tumour and liver toxicity in patients with liver malignancies who underwent hepatic arterial ${ }^{90} \mathrm{Y}$ resin microsphere treatment [42]. In this clinical report, doses up to 99.5 Gy to uninvolved liver are well tolerated with no clinical venoocclusive disease or liver failure. The lowest tumour dose producing a detectable response is $40.1 \mathrm{~Gy}$. The further utilization of ${ }^{99} \mathrm{mTc}$ - MAA imaging to determine tumour and liver blood flow for clinical treatment planning and the calculation of administered activity could improve clinical outcomes. However, Radioembolization therapy of ${ }^{90} \mathrm{Y}$-Microspheres of other low incidence liver cancers and liver metastasis of low incidence extrahepatic cancers needs more clinical studies. Accumulating clinical data would provide fundamental guidance for clinical and therapeutic efforts for disease types for which clinical trials are not feasible due to their low incidence or for the vast majority of those afflicted who do not meet eligibility criteria.

\section{Advantages}

Perhaps the biggest advantage of ${ }^{90} \mathrm{Y}$ is that it targets the cancerous tissue more exclusively than conventional radiation which affects whole liver and since the normal hepatic cells have even lower threshold for radiation than the cancerous ones, the majority of patients develop hepatic dysfunction after conventional radiation [43-45]. Furthermore, in comparison to patients left untreated in TACE, the patients, who underwent SIRT, have a greater chance of up to 1 year survival [43]. Another definite advantage in the field of ${ }^{90} \mathrm{Y}$ is its use in patients with HCC and portal vein thrombosis (PVT) which occurs in almost one third of the patients and makes them very poor candidates for TACE due to its fatal complications. According to Alkalbani, et al. [45], the median survival dates with ${ }^{90} \mathrm{Y}$ increased from less than 100 days to 469 days in those who received the therapy comparing to those who left untreated with TACE due to PVT [45]. An emerging alternative to ${ }^{90} \mathrm{Y}$ radioembolization is drug-eluding beads impregnated with irinotecan (DEBIRI). The unique properties of the beads allow for fixed dosing and the ability to release the chemotherapeutic agent in a sustained and controlled manner. This reduces systemic toxicity and theoretically improves tumour response. Initial evaluations of DEBIRI have demonstrated that it has acceptable toxicity and has promising activity [46,47]. In addition, ${ }^{90} \mathrm{Y}$ radioembolization therapy for liver cancers is safe due to beta emission. Patients can be treated as outpatients with relative easy prevention of radiation exposure to public and close family members.

\section{Side Effects and Toxicity}

Although selective beam therapy is wildly spreading, literature on the side effects of this procedure has not been thoroughly understood. Some more recognized and incriminated complications include: post radio embolization syndrome (PRS), hepatic dysfunction, biliary complications, portal hypertension, radiation pneumonitis, gastrointestinal ulcers, vascular injury, and lymphopenia [21]. Lymphopenia due to leaching of ${ }^{90} \mathrm{Y}$ was reported in early phases. Lung injury due to chemical pneumonitis can occur and is considered as a life threatening condition in patients with marked hepatopulmonary shunting [48,49]. PRS includes fatigue, nausea, vomiting, anorexia, fever, abdominal discomfort, and cachexia, occurring in $20-55 \%$ of patients. Steroids and antiemetic agents may decrease the incidence of PRS. However, there is no supported evidence of infections with opportunistic agents in treatment with ${ }^{90} \mathrm{Y}$ microsphere biliary complications, including cholecystitis and biliary strictures.

The radiology literature reports a significantly wide range (3\%-24\%) of the incidence of GI complications from SIRT [48-50]. According to the study done by Konda, et al. [51], significant GI complications and symptoms could be nausea/vomiting, odynophagia, hematemesis, and melena. Also, radiation ulcers can occur in the gastric antrum, pylorus, and duodenum [51].

Early stasis occurred in approximately $20 \%$ of infusions with similar incidences in hyper and hypovascular tumours. Whole-liver therapy reduced the incidence of stasis. However, stasis did not appear to affect initial imaging outcomes [52].

\section{Contraindications}

In many classification systems, a bilirubin greater than $2 \mathrm{mg} / \mathrm{dl}$ in the absence of a correctable obstructive reason is considered to be a contraindication [21]. Massive hepatopulmonary shunting and reflux into that supply of the gastro duodenal region will put the patient at risk of radiation pneumonitis and gastric ulceration $[43,53]$. In the retrospective study by Goin, et al. [54], predictive factors of 3 month survival identified as having bigger tumour size that $70 \%$ in those with local tumour, amino transaminases level more than 5 times of upper limit, bilirubin level greater than $2 \mathrm{mg} / \mathrm{dl}$, and albumin less $3 \mathrm{~g} / \mathrm{dl}$ [54].

\section{Conclusion}

Radioembolization represents an effective, repeatable and palliative therapy for patients with primary and secondary liver cancers. The utility of ${ }^{90} \mathrm{Y}$ microsphere therapy is being evaluated by performing series of clinical trials. Accumulating clinical data would provide fundamental guidance for clinical and therapeutic efforts for disease types for which clinical trials are not feasible due to their low incidence or for the vast majority of those afflicted who do not meet eligibility criteria.

\section{References}

1. El-Serag HB, Rudolph KL (2007) Hepatocellular carcinoma: epidemiology and molecular carcinogenesis. See comment in PubMed Commons below Gastroenterology 132: 2557-2576.

2. Gomes MA, Priolli DG, Tralhão JG, Botelho MF (2013) Hepatocellular carcinoma: epidemiology, biology, diagnosis, and therapies. See comment in PubMed Commons below Rev Assoc Med Bras 59: 514-524. 
3. Michelotti GA, Machado MV, Diehl AM (2013) NAFLD, NASH and liver cancer. See comment in PubMed Commons below Nat Rev Gastroenterol Hepatol 10: 656-665.

4. Llovet JM, Burroughs A, Bruix J (2003) Hepatocellular carcinoma. See comment in PubMed Commons below Lancet 362: 1907-1917.

5. Peck-Radosavljevic M (2014) Drug therapy for advanced-stage liver cancer. See comment in PubMed Commons below Liver Cancer 3: 125-131.

6. Nakagomi R, Tateishi R, Shiina S, Imamura J, Fujiwara N, et al. (2014) Drastically reduced neoplastic seeding related to radiofrequency ablation for hepatocellular carcinoma. See comment in PubMed Commons below Am J Gastroenterol 109: 774-776.

7. Shoreibah MG, Bloomer JR, McGuire BM, Massoud OI (2014) Surveillance for hepatocellular carcinoma: evidence, guidelines and utilization. See comment in PubMed Commons below Am J Med Sci 347: 415-419.

8. Méndez-Sánchez N, Ridruejo E, Alves de Mattos A, Chávez-Tapia NC Zapata R, et al. (2014) Latin American Association for the Study of the Liver (LAASL) Clinical Practice Guidelines: Management of Hepatocellular Carcinoma. Ann Hepatol. 13 Suppl 1: 4-40.

9. Schelhorn J, Theysohn J, Ertle J, Schlaak JF, Mueller S, et al. (2014) Selective internal radiation therapy of hepatic tumours: is coiling of the gastroduodenal artery always beneficial? See comment in PubMed Commons below Clin Radiol 69: e216-222.

10. Theysohn JM, Ertle J, Müller S, Schlaak JF, Nensa F, et al. (2014) Hepatic volume changes after lobar selective internal radiation therapy (SIRT) of hepatocellular carcinoma. See comment in PubMed Commons below Clin Radiol 69: 172-178.

11. Stubbs RS, Wickremesekera SK (2004) Selective internal radiation therapy (SIRT): a new modality for treating patients with colorectal liver metastases. See comment in PubMed Commons below HPB (Oxford) 6: 133-139.

12. Wang LM, Jani AR, Hill EJ, Sharma RA (2013) Anatomical basis and histopathological changes resulting from selective internal radiotherapy for liver metastases. See comment in PubMed Commons below J Clin Pathol 66: 205-211.

13. Tapping CR, Dixon S, Little MW, Boardman P, Sharma RA, et al. (2012) Liquid embolization of the gastroduodenal artery before selective internal radiotherapy (SIRT). See comment in PubMed Commons below Clin Radiol 67: 789-792.

14. Ibrahim SM, Nikolaidis P, Miller FH, Lewandowski RJ, Ryu RK, et al. (2009) Radiologic findings following Y90 radioembolization for primary liver malignancies. See comment in PubMed Commons below Abdom Imaging 34: 566-581.

15. Salem R, Lewandowski RJ, Mulcahy MF, Riaz A, Ryu RK, et al. (2010) Radioembolization for hepatocellular carcinoma using Yttrium-90 microspheres: a comprehensive report of long-term outcomes. See comment in PubMed Commons below Gastroenterology 138: 52-64.

16. Ariel IM, Pack GT (1967) Treatment of inoperable cancer of the liver by intra-arterial radioactive isotopes and chemotherapy. See comment in PubMed Commons below Cancer 20: 793-804.

17. Murthy R, Nunez R, Szklaruk J, Erwin W, Madoff DC, et al. (2005) Yttrium-90 microsphere therapy for hepatic malignancy: devices, indications, technical considerations, and potential complications. See comment in PubMed Commons below Radiographics 25 Suppl 1: S41-55.

18. Daghir AA, Gungor H, Haydar AA, Wasan HS, Tait NP (2012) Embolisation of the gastroduodenal artery is not necessary in the presence of reversed flow before yttrium-90 radioembolisation. See comment in PubMed Commons below Cardiovasc Intervent Radiol 35: 839-844.

19. Wu SY, Kuo JW, Chang TK, Liu RS, Lee RC, et al. (2012) Preclinical characterization of 18F-MAA, a novel PET surrogate of 99mTc-MAA See comment in PubMed Commons below Nucl Med Biol 39: 1026-1033.

20. Lenoir L, Edeline J, Rolland Y, Pracht M, Raoul JL, et al. (2012) Usefulness and pitfalls of MAA SPECT/CT in identifying digestive extrahepatic uptake when planning liver radioembolization. See comment in PubMed Commons below Eur J Nucl Med Mol Imaging 39: 872-880.

21. Kao YH, Tan EH, Ng CE, Goh SW (2011) Clinical implications of the body surface area method versus partition model dosimetry for yttrium-90 radioembolization using resin microspheres: a technical review. See comment in PubMed Commons below Ann Nucl Med 25: 455-461.

22. Karunanithy N, Gordon F, Hodolic M, Al-Nahhas A, Wasan HS, et al. (2011) Embolization of hepatic arterial branches to simplify hepatic blood flow before yttrium 90 radioembolization: a useful technique in the presence of challenging anatomy. See comment in PubMed Commons below Cardiovasc Intervent Radiol 34: 287-294.

23. Vouche M, Habib A, Ward TJ, Kim E, Kulik L, et al. (2014) Unresectable solitary hepatocellular carcinoma not amenable to radiofrequency ablation: Multicenter radiology-pathology correlation and survival of radiation segmentectomy. Hepatology. 60: 192-201.

24. Rana N, Ju AW, Bazylewicz M, Kallakury B, He AR, et al. (2013) Yttrium-90 Radioembolization in Patients with Hepatocellular Carcinoma Who have Previously Received Sorafenib. See comment in PubMed Commons below Front Oncol 3: 323.

25. Saxena A, Bester L, Shan L, Perera M, Gibbs P, et al. (2014) A systematic review on the safety and efficacy of yttrium-90 radioembolization for unresectable, chemorefractory colorectal cancer liver metastases. See comment in PubMed Commons below J Cancer Res Clin Oncol 140: 537-547.

26. Ibrahim SM, Nikolaidis P, Miller FH, Lewandowski RJ, Ryu RK, et al. (2009) Radiologic findings following Y90 radioembolization for primary liver malignancies. See comment in PubMed Commons below Abdom Imaging 34: 566-581.

27. Ali SM (2011) Radioembolization for hepatocellular carcinoma using TheraSphere. See comment in PubMed Commons below Saudi J Gastroenterol 17: 215-217.

28. Nicolay NH, Berry DP, Sharma RA (2009) Liver metastases from colorectal cancer: radioembolization with systemic therapy. See comment in PubMed Commons below Nat Rev Clin Oncol 6: 687-697.

29. Gulec SA, Fong Y (2007) Yttrium 90 microsphere selective internal radiation treatment of hepatic colorectal metastases. See comment in PubMed Commons below Arch Surg 142: 675-682.

30. Cianni R, Urigo C, Notarianni E, Saltarelli A, Salvatori R, et al. (2009) Selective internal radiation therapy with SIR-spheres for the treatment of unresectable colorectal hepatic metastases. See comment in PubMed Commons below Cardiovasc Intervent Radiol 32: 1179-1186.

31. Sideras PA, Sofocleous CT, Brody LA, Siegelbaum RH, Shah RP, et al. (2012) Superselective internal radiation with Yttrium-90 microspheres in the management of a chemorefractory testicular liver metastasis. Cardiovasc Intervent Radiol 35: 426-429.

32. Mouli S, Memon K, Baker T, Benson AB 3rd, Mulcahy MF, et al. (2013) Yttrium-90 radioembolization for intrahepatic cholangiocarcinoma: safety, response, and survival analysis. See comment in PubMed Commons below J Vasc Interv Radiol 24: 1227-1234.

33. Rafi S, Piduru SM, El-Rayes B, Kauh JS, Kooby DA, et al. (2013) Yttrium-90 radioembolization for unresectable standardchemorefractory intrahepatic cholangiocarcinoma: survival, efficacy, and safety study. Cardiovasc Intervent Radiol. 36: 440-448.

34. Rosenbaum CE, van den Bosch MA, Veldhuis WB, Huijbregts JE, Koopman M, et al. (2013) Added value of FDG-PET imaging in the diagnostic workup for yttrium-90 radioembolisation in patients with colorectal cancer liver metastases. See comment in PubMed Commons below Eur Radiol 23: 931-937.

35. Pellerin O, Lin M, Bhagat N, Shao W, Geschwind JF (2013) Can C-arm cone-beam CT detect a micro-embolic effect after TheraSphere radioembolization of neuroendocrine and carcinoid liver metastasis? Cancer Biother Radiopharm. 28: 459-465.

36. Saxena A, Kapoor J, Meteling B, Morris DL, Bester L (2014) Yttrium-90 radioembolization for unresectable, chemoresistant breast cancer liver 
metastases: a large single-center experience of 40 patients. Ann Surg Oncol. 21: 1296-1303.

37. Hilgard P, Hamami M, Fouly AE, Scherag A, Müller S, et al. (2010) Radioembolization with yttrium-90 glass microspheres in hepatocellular carcinoma: European experience on safety and long-term survival. See comment in PubMed Commons below Hepatology 52: 1741-1749.

38. PeynircioÄŸlu B, Cil B, Bozkurt F, Aydemir E, UÄŸur O, et al. (2010) Radioembolization for the treatment of unresectable liver cancer: initial experience at a single center. See comment in PubMed Commons below Diagn Interv Radiol 16: 70-78.

39. Rana N, Ju AW, Bazylewicz M, Kallakury B, He AR, et al. (2013) Yttrium-90 Radioembolization in Patients with Hepatocellular Carcinoma Who have Previously Received Sorafenib. See comment in PubMed Commons below Front Oncol 3: 323.

40. Teo JY, Goh BK, Cheah FK, Allen JC, Lo RH, et al. (2014) Underlying liver disease influences volumetric changes in the spared hemiliver after selective internal radiation therapy with $90 \mathrm{Y}$ in patients with hepatocellular carcinoma. J Dig Dis.

41. Lewandowski RJ, Memon K, Mulcahy MF, Hickey R, Marshall K, et al. (2014) Twelve-year experience of radioembolization for colorectal hepatic metastases in 214 patients: survival by era and chemotherapy. See comment in PubMed Commons below Eur J Nucl Med Mol Imaging .

42. Gulec SA, Mesoloras G, Dezarn WA, McNeillie P, Andrew S Kennedy AS (2007) Safety and efficacy of Y-90 microsphere treatment in patients with primary and metastatic liver cancer: The tumour selectivity of the treatment as a function of tumour to liver flow ratio. Journal of Translational Medicine. 5: 1-9.

43. Geschwind JF, Salem R, Carr BI, Soulen MC, Thurston KG, et al. (2004) Yttrium-90 microspheres for the treatment of hepatocellular carcinoma. See comment in PubMed Commons below Gastroenterology 127: S194-205.

44. Llovet JM, Bustamante J, Castells A, Vilana R, Ayuso Mdel C, et al. (1999) Natural history of untreated nonsurgical hepatocellular carcinoma: rationale for the design and evaluation of therapeutic trials. See comment in PubMed Commons below Hepatology 29: 62-67.

45. Al-Kalbani A, Kamel Y (2008) Y-90 microshperes in the treatment of unresectable hepatocellular carcinoma. See comment in PubMed Commons below Saudi J Gastroenterol 14: 90-92.

46. Fiorentini G, Aliberti C, Tilli M, Mulazzani L, Graziano F, et al. (2012) Intra-arterial infusion of irinotecan-loaded drugeluting beads (DEBIRI) versus intravenous therapy (FOLFIRI) for hepatic metastases from colorectal cancer: final results of a phase III study. Anticancer Res 32: 1387-1395.

47. Martin LK, Cucci A, Wei L, Rose J, Blazer M, et al. (2012) Yttrium-90 radioembolization as salvage therapy for colorectal cancer with liver metastases. See comment in PubMed Commons below Clin Colorectal Cancer 11: 195-199.

48. Salem R, Parikh P, Atassi B, Lewandowski RJ, Ryu RK, et al. (2008) Incidence of radiation pneumonitis after hepatic intra-arterial radiotherapy with yttrium-90 microspheres assuming uniform lung distribution. See comment in PubMed Commons below Am J Clin Oncol 31: 431-438.

49. Choi YW, Munden RF, Erasmus JJ, Park KJ, Chung WK, et al. (2004) Effects of radiation therapy on the lung: radiologic appearances and differential diagnosis. See comment in PubMed Commons below Radiographics 24: 985-997.

50. Gray B, Van Hazel G, Hope M, Burton M, Moroz P, et al. (2001) Randomised trial of SIR-Spheres plus chemotherapy vs. chemotherapy alone for treating patients with liver metastases from primary large bowel cancer. See comment in PubMed Commons below Ann Oncol 12: 1711-1720.

51. Konda A, Savin MA, Cappell MS, Duffy MC (2009) Radiation microsphere-induced GI ulcers after selective internal radiation therapy for hepatic tumours: an underrecognized clinical entity. Gastrointestinal Eendoscopy 70: 561-567.

52. Piana PM, Bar V, Doyle L, Anne R, Sato T, et al. (2014) Early arterial stasis during resin-based yttrium-90 radioembolization: incidence and preliminary outcomes. See comment in PubMed Commons below HPB (Oxford) 16: 336-341.

53. Murthy R, Nunez R, Szklaruk J, Erwin W, Madoff DC, et al. (2005) Yttrium-90 microsphere therapy for hepatic malignancy: Devices, indications, technical considerations and potential complications. Radiographics 25: S41-S55.

54. Goin JE, Salem R, Carr BI, Dancey JE, Soulen MC, et al. (2005) Treatment of unresectable hepatocellular carcinoma with intrahepatic yttrium 90 microspheres: A risk-stratification analysis. J Vasc Interv Radiol.16: 195-203. 